\title{
Identification of serum proteins AHSG, FGA and APOA-I as diagnostic biomarkers for gastric cancer
}

Feiyu Shi ${ }^{1 \dagger}$, Hong $\mathrm{Wu}^{1 \dagger}$, Kai Qu${ }^{2}$, Qi Sun ${ }^{1}$, Fanni $\mathrm{Li}^{3}$, Chengxin Shi ${ }^{1}$, Yaguang $\mathrm{Li}^{1}$, Xiaofan Xiong ${ }^{4}$, Qian Qin ${ }^{1}$, Tianyu Yu ${ }^{1}$, Xin Jin ${ }^{1}$, Liang Cheng ${ }^{2}$, Qingxia Wei ${ }^{5}$, Yingchao Li ${ }^{6}$ and Junjun She ${ }^{1 *}$ (D)

\begin{abstract}
Background: The development of clinically accessible biomarkers is critical for the early diagnosis of gastric cancer (GC) in patients. High-throughput proteomics techniques could not only effectively generate a serum peptide profile but also provide a new approach to identify potentially diagnostic and prognostic biomarkers for cancer patients.

Methods: In this study, we aim to identify potentially discriminating serum biomarkers for GC. In the discovery cohort, we screened potential biomarkers using magnetic-bead-based purification and matrix-assisted laser desorption/ionization time-of-flight mass spectrometry in 64 samples from $32 \mathrm{GC}$ patients that were taken both pre- and post-operatively and 30 healthy volunteers that served as controls. In the validation cohort, the expression patterns and diagnostic values of serum FGA, AHSG and APOA-I were further confirmed by ELISA in 42 paired GC patients (preand post-operative samples from 16 patients with pathologic stage I/II and 26 with stage III/IV), 30 colorectal cancer patients, 30 hepatocellular carcinoma patients, and 28 healthy volunteers.
\end{abstract}

Results: ClinProTools software was used and annotated 107 peptides, 12 of which were differentially expressed among three groups $(P<0.0001$, fold $>1.5)$. These 12 peptide peaks were further identified as FGA, AHSG, APOA-I, HBB, TXNRD1, GSPT2 and CAKP5. ELISA data suggested that the serum levels of FGA, AHSG and APOA-I in GC patients were significantly different compared with healthy controls and had favorable diagnostic values for GC patients. Moreover, we found that the serum levels of these three proteins were associated with TNM stages and could reflect tumor burden.

Conclusion: Our findings suggested that FGA, AHSG and APOA-I might be potential serum biomarkers for GC diagnosis.

Keywords: Gastric cancer, Biomarker, APOA-I, AHSG, FGA

\section{Background}

Gastric cancer (GC) is the fourth most common cancer with almost 1000,000 new cases diagnosed every year [1]. The incidence of GC is highest in Eastern Asia, especially in China, which alone accounts for nearly $50 \%$ of the world's cases [2]. Moreover, GC is the second leading

\footnotetext{
*Correspondence: 465537199@qq.com

${ }^{\dagger}$ Feiyu Shi and Hong Wu have contributed equally to this work. 1 Department of General Surgery, The First Affiliated Hospital of Xi'an Jiao Tong University, 277 Yanta West Road, Xi'an 710061, Shaanxi, China Full list of author information is available at the end of the article
}

fatal cancer subtype, and approximately 498,000 Chinese patients died from GC in 2015 [3]. The high mortality rate of GC is mainly due to delayed diagnosis, at which time the cancer has advanced to an inoperable stage and can no longer be eradicated by surgical resection [4]. There are non-specific symptoms displayed in GC patients at the early stages [5]. Therefore, exploring novel biomarkers for GC patients will help monitor tumor status and guide clinical treatment.

Serum tumor biomarkers can be secreted by tumor cells or by normal cells responding to the malignant behavior of tumors [6]. For decades, serum-based 
biomarkers were considered the most important biomarkers to reflect tumor burden and have been applied for cancer diagnosis and post-operation monitoring. The conventional serum-based biomarkers for GC, such as carcino-embryonic antigen (CEA), carbohydrate antigen 19-9 (CA19-9) and CA72-4, did not have favorable specificity and sensitivity, which always resulted in delayed diagnosis [7, 8]. Ebert MP et al. stated that the sensitivities of above three biomarkers are only 16-63, 20-56, and $18-51 \%$, respectively [9].

In recent years, several high-throughput proteomics techniques have been applied in serum samples to uncover novel diagnostic markers [10]. Matrix-assisted laser desorption/ionization time-of-flight mass spectrometry (MALDI-TOF-MS) is becoming a standard tool in protein analysis in particular [11-13]. In this study, we first evaluated a discovery group that included $32 \mathrm{GC}$ patients and 30 healthy volunteers and employed MALDI-TOF-MS to identify peptides that were candidate biomarkers for GC. Next, we evaluated a validation group that included 42 paired GC patients, 30 colorectal cancer (CRC) patients, 30 hepatocellular carcinoma (HCC) patients, and 28 healthy volunteers and performed enzyme-linked immunosorbent assay (ELISA) to validate the diagnostic values of the candidate biomarkers identified in the first step.

\section{Methods}

\section{Patient selection and sample preparation}

The research protocol was approved by the Ethics and the Human Research Review Committee of Xi'an Jiao Tong University. All subjects signed a consent form before participating in this research study, which was approved by the Institutional Review Board of Xi'an Jiao Tong University. All experiments were carried out in accordance with the approved guidelines. A total of 266 serum samples from 192 individuals were collected from the Department of General Surgery, Department of Gastroenterology, the Department of Physical Examination, the First Affiliated Hospital of Xi'an Jiao Tong University, China, from March 2016 to April 2017. The discovery cohort consisted of 32 pairs of serum samples from 32 pre- and post-operative GC patients as well as 30 healthy controls. The validation cohort was composed of 42 pairs of serum samples from GC patients (16 pairs are at I/II stage, and 26 pairs are at III/IV stage), 30 CRC patients, $30 \mathrm{HCC}$ patients, and 28 healthy volunteers. The diagnosis of GC, CRC and HCC was confirmed by pathological diagnosis. The discovery cohort and validation cohort are completely non-overlapping. Moreover, the healthy control groups were gender- and age-matched with the cancer groups. The characteristic information of all subjects is shown in Table 1.

The exclusion criteria for subjects were as follows: (1) patients with a known history of any other tumors and any obvious inflammatory diseases, such as liver cirrhosis, chronic renal disease, and diabetes mellitus; (2) patients with a known history of any surgical operations, chemotherapy or radiotherapy before collection of the serum; and (3) patients with a known history of receiving blood transfusion within a month before collection of the serum.

All blood samples were obtained from non-fasting patients or healthy controls in the morning. The serum samples were collected in 10-cc separator tubes (BD, \#367820) and were kept at $4{ }^{\circ} \mathrm{C}$ for $1 \mathrm{~h}$, then centrifuged at $3000 \mathrm{rpm}$ for $10 \mathrm{~min}$ at $4{ }^{\circ} \mathrm{C}$. The serum samples were distributed into $400-\mu \mathrm{L}$ aliquots and stored at $-80{ }^{\circ} \mathrm{C}$ until use.

Table 1 Demographics of all subjects enroll in this study

\begin{tabular}{|c|c|c|c|c|c|c|}
\hline \multirow[t]{2}{*}{ Patients characteristics } & \multicolumn{2}{|c|}{ Discovery cohort } & \multicolumn{4}{|c|}{ Validation cohort } \\
\hline & Control group & GC & Control group & GC & CRC & $\mathrm{HCC}$ \\
\hline Number of cases & 30 & 32 & 28 & 42 & 30 & 30 \\
\hline \multicolumn{7}{|l|}{ Gender } \\
\hline Male/female & $20 / 10$ & $22 / 10$ & $18 / 10$ & $28 / 14$ & $21 / 11$ & $22 / 8$ \\
\hline Age (year) & $65.44 \pm 7.85$ & $63.97 \pm 7.42$ & $62.48 \pm 8.68$ & $63.38 \pm 9.35$ & $61.80 \pm 9.42$ & $60.73 \pm 9.28$ \\
\hline \multicolumn{7}{|l|}{ pTNM stage } \\
\hline 1 & - & 6 & - & 5 & 6 & 4 \\
\hline$\|$ & - & 10 & - & 11 & 10 & 9 \\
\hline III & - & 12 & - & 21 & 11 & 14 \\
\hline IV & - & 2 & - & 5 & 3 & 3 \\
\hline
\end{tabular}


MS analysis: magnetic beads-based immobilized metal-ion affinity chromatography (MB-IMAC-Cu) fractionation and MALDI-TOF-MS

Magnetic Beads-based Immobilized Metal-ion Affinity Chromatography (MB-IMAC-Cu) (ClinProt purification reagent sets; Bruker Daltonics, Bremen, Germany) was used for enrichment of serum peptides followed by MALDI-TOF-MS analysis. A total of 94 serum samples were fractionated according to instructions provided by Bruker Daltonics. Briefly, $5 \mu \mathrm{l}$ of magnetic beads was pretreated with $50 \mu \mathrm{l}$ of binding buffer, and the supernatant was carefully discarded. The magnetic beads were re-suspended in $20 \mu \mathrm{l}$ of binding buffer in a PCR tube, and then $5 \mu \mathrm{l}$ of serum sample was added and mixed gently. The mixtures were incubated at room temperature for $5 \mathrm{~min}$ and separated in the magnetic separator. The beads were washed once with $100 \mu \mathrm{l}$ of wash buffer, and the peptides and proteins were eluted with $10 \mu \mathrm{l}$ of elution buffer from beads. Then, $1 \mu \mathrm{l}$ of the eluted peptides and proteins and $1 \mu \mathrm{l}$ of a mixture containing $3 \mathrm{mg} / \mathrm{ml} \alpha$-cyano-4hydroxy-cinnamic acid (Bruker) in 50\% acetonitrile and $0.5 \%$ trifluoroacetic acid was spotted onto the MALDI AnchorChip surface. Samples were spotted in triplicate to evaluate the reproducibility of this method.

\section{Data analysis with ClinProTools}

Air-dried targets were immediately tested with calibrated Autoflex III MALDI-TOF-MS (Bruker), flexControl version 3.0 software (Bruker), via an optimized measuring protocol. The settings of the instrument were as follows: ion source $1,20.00 \mathrm{kV}$; ion source $2,18.90 \mathrm{kV}$; lens, $6.50 \mathrm{kV}$; and pulsed ion extraction, $120 \mathrm{~ns}$. Ionization was achieved by irradiation with a crystal laser operating at $200.0 \mathrm{~Hz}$. A standard calibration mixture of peptides and proteins (mass range $1-10 \mathrm{kDa}$ ) was used for mass calibration. For each MALDI spot, 1200 spectra were acquired (200 laser shots at 6 different spot positions). All tests were performed in a blinded manner, including the serum analysis of different groups. The Flex analysis software (version 3.0; Bruker) was applied for all serum data analysis. Recognition of peptide patterns was analyzed by ClinProTools version 2.2 software (Bruker).

\section{Peptide identification by LC-ESI-MS/MS}

After completing the statistical analysis, the peptides were identified using liquid chromatography-mass spectrometry, which combined Nano Acquity UPLC liquid chromatography (Waters, USA) with an LTQ Orbitrap XL mass spectrometer system (Thermo Fisher Scientific, USA). The Peptide mixture solutions purified by MB-IMAC-Cu trapping used a captrap C18 $(2 \mathrm{~mm} \times 0.5 \mathrm{~mm}$ ) column (Michrom Corporation, USA) and an analytical Magic C18, AQ $(100 \mu \mathrm{m} \times 150 \mathrm{~mm})$ column (Michrom Corporation). Mobile phase A was a solution of $5 \%$ acetonitrile and $0.1 \%$ formic acid, and mobile phase B was a solution of $90 \%$ acetonitrile and $0.1 \%$ formic acid. Peptide mixtures were injected into the trap column with a flow of $20 \mu \mathrm{l} / \mathrm{min}$ for $5 \mathrm{~min}$ and then eluted with a three-step linear gradient, starting from $5 \%$ $\mathrm{B}$ to $45 \% \mathrm{~B}$ for $40 \mathrm{~min}$, increased to $80 \% \mathrm{~B}$ for $1 \mathrm{~min}$, and then held at $80 \% \mathrm{~B}$ for $4 \mathrm{~min}$. The column was re-equilibrated at the initial conditions for $15 \mathrm{~min}$. The column flow rate was maintained at $500 \mathrm{nl} / \mathrm{min}$, and the column temperature was maintained at $35^{\circ} \mathrm{C}$.

Electrospray voltage of $1.9 \mathrm{kV}$ versus the inlet of the mass spectrometer was used. The LTQ Orbitrap XL mass spectrometer was operated in the data-dependent mode to switch automatically between MS and MS/MS acquisition. Survey full scan MS spectra with two microscans $(\mathrm{m} / \mathrm{z} 400-2000)$ were acquired in the Obitrap with a mass resolution of 100,000 at $\mathrm{m} / \mathrm{z} 400$, followed by eight sequential LTQ-MS/MS scans. Dynamic exclusion was used with two repeat counts, consisting of a $10 \mathrm{~s}$ repeat duration and a $60 \mathrm{~s}$ exclusion duration. For MS/ MS, precursor ions were activated using $25 \%$ normalized collision energy at the default activation $\mathrm{q}$ of 0.25 . All MS/MS spectra were profiled with SEQUEST [v.28 (revision 12), Thermo Electron Corp.] which searched the human International Protein index (IPI) database (IPI human v3.64 fasta with 71,983 entries) and the UniprotKB (http://www.uniprot.org) for peptide-to-spectral matching. To minimize false positives, a decoy database containing all of the reverse protein sequences was added to this database. The search parameters were as follows: no enzyme digestion, the variable modification was the oxidation of methionine, a peptide mass tolerance of $20 \mathrm{ppm}$, and a fragment ion tolerance of 1.0 Da.

The resulting filter parameters were as follows: ${ }^{\Delta} \mathrm{Cn} \geq 0.10$, Xcorr $\geq 2.3$ for two charged ions, Xcorr $\geq 2.6$ for three charged ions, Xcorr $\geq 3.0$ for four or more charged state ions, and FDR $<0.01$. The errors were less than $0.1 \mathrm{Da}$ in the $\mathrm{m} / \mathrm{z}$ of peptide determined by LC-MS.

\section{Enzyme-linked immunosorbent assay (ELISA)}

All serum samples were run in triplicate and analyzed in a blinded fashion in triplicate. The concentrations of Isoform I of Fibrinogen alpha chain precursor (FGA), Alpha-2-HS-glycoprotein precursor (AHSG) and Apolipoprotein A-I precursor (APOA1) were quantified with a Human FGA ELISA Kit (Elisa Biotech, \#: CKE93791H), a Human AHSG ELISA Kit (Elisa Biotech, \#: CK-E95306H), and a Human ApoA-1 ELISA kit (Elisa Biotech, \#: CK-E11517H), respectively. Standard curves were generated and used to determine the concentrations of FGA, AHSG and APOA-1 in the samples analyzed. 


\section{Statistical analysis}

Statistical analysis was performed with GraphPad Prism version 6.0 (GraphPad Software, La Jolla, CA, USA). All data are shown as the mean \pm SD. $P<0.05$ was considered significant. Comparisons among multiple groups were performed via repeated measures analysis of variance and the least significant difference test. Student's $t$ test was used to analyze the ELISA data. ROC curves were utilized to assess the diagnostic value of FGA, AHSG, and APOA-I.

\section{Results}

\section{Serum proteomic profiling of GC patients and healthy controls}

As shown in Fig. 1b, the reproducibility and stability of the mass spectra data were closely reproducible in triplicate samples of each group. We then performed mass spectrometry-based proteomics via the MALDITOF-MS method (Fig. 1a). Our data revealed that the mass spectra differed among the pre-operative GC patients (red), post-operative GC patients (blue) and healthy controls (green) (Fig. 1). Additionally, the serum samples fractionated by MB-IMAC-Cu and MALDITOF-MS showed that pre-operative GC patients (red), post-operative GC patients (blue) and controls (green) had proteomic profiles that ranged from 1000 to $10,000 \mathrm{Da}$ (Fig. 1c). Principal component analysis revealed that pre-operative GC patients (red), postoperative GC patients (blue) and control (green) samples could be distinguished by several peptides (Fig. 1d, e), which suggested the possibility of exploring serum biomarkers to separate GC patients from control subjects.
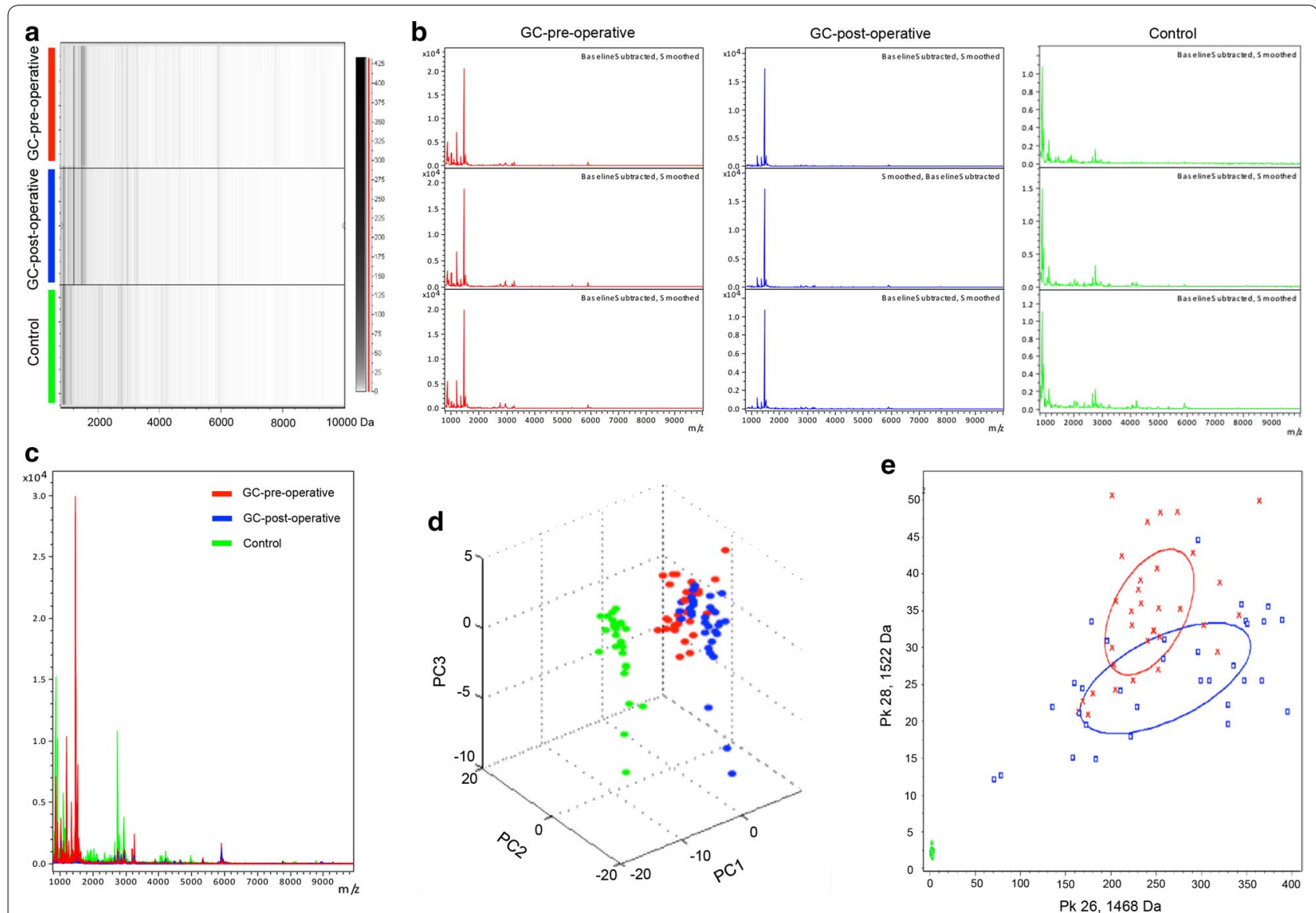

Fig. 1 Reproducibility of mass spectra generated in individuals from different groups and the comparative analysis of serum proteomic profiling between different groups. a Gel view of mass spectra from healthy control (green), GC pre-operative (red) and GC post-operative (blue) serum samples, in the mass range from 1000 to $10000 \mathrm{Da}$. b Representative mass spectra of three samples in each group in the mass range from 1000 to $10,000 \mathrm{Da}$, showing high reproducibility and stability between replicates. c Overall sum of the spectra in the mass range from 1000 to 10,000 Da obtained from all GC patients pre-operation (red) and post-operation (blue), as well as healthy controls (green). $\mathbf{d}$ 3D plot and bivariate plot e of pre-operative GC patients (red), healthy controls (green), and post-operative GC patients (blue) in the PCA 


\section{Selection of differential expressed peptides and diagnostic model testing}

ClinProTools software (version 2.2, Bruker) was used to identify a total of 107 different peaks from serum samples. Among them, 12 peaks were significantly different among pre-operative and post-operative $\mathrm{GC}$ patients and healthy controls $(P<0.0001$, fold change $>1.5)($ Fig. 2$)$ and showed a response to therapy and a tendency to return to healthy control values after the operation. Peptide peaks 1-8 (peak 1, m/z: 1265.49 Da; peak 2, m/z: 1352.84 Da; peak 3, m/z: 1406.85 Da; peak 4, m/z: 1506.07 Da; peak 5, m/z: 1521.93 Da; peak 6, m/z: 1539.22 Da; peak 7, m/z:
1575.90 Da; and peak 8, m/z: $1621.81 \mathrm{Da})$ were up-regulated, and peaks 9-12 (peak 9, m/z: 2663.12 Da; peak 10, m/z: 2716.91 Da; peak 11, m/z: 2865.39 Da; and peak 12, $\mathrm{m} / \mathrm{z}: 4213.82 \mathrm{Da}$ ) were down-regulated in pre-operative GC patients compared with healthy controls (Table 2). The relative expression levels of the above 12 peptide peaks among healthy controls (green), pre-operative GC (red), and post-operative GC (blue) are shown in Fig. 3a. The receiver operating characteristic (ROC) curves of 12 differentially expressed peptides between GC patients and healthy controls are shown in Fig. 3b. The area under ROC (AUC) values of all peptides were more than 0.8,
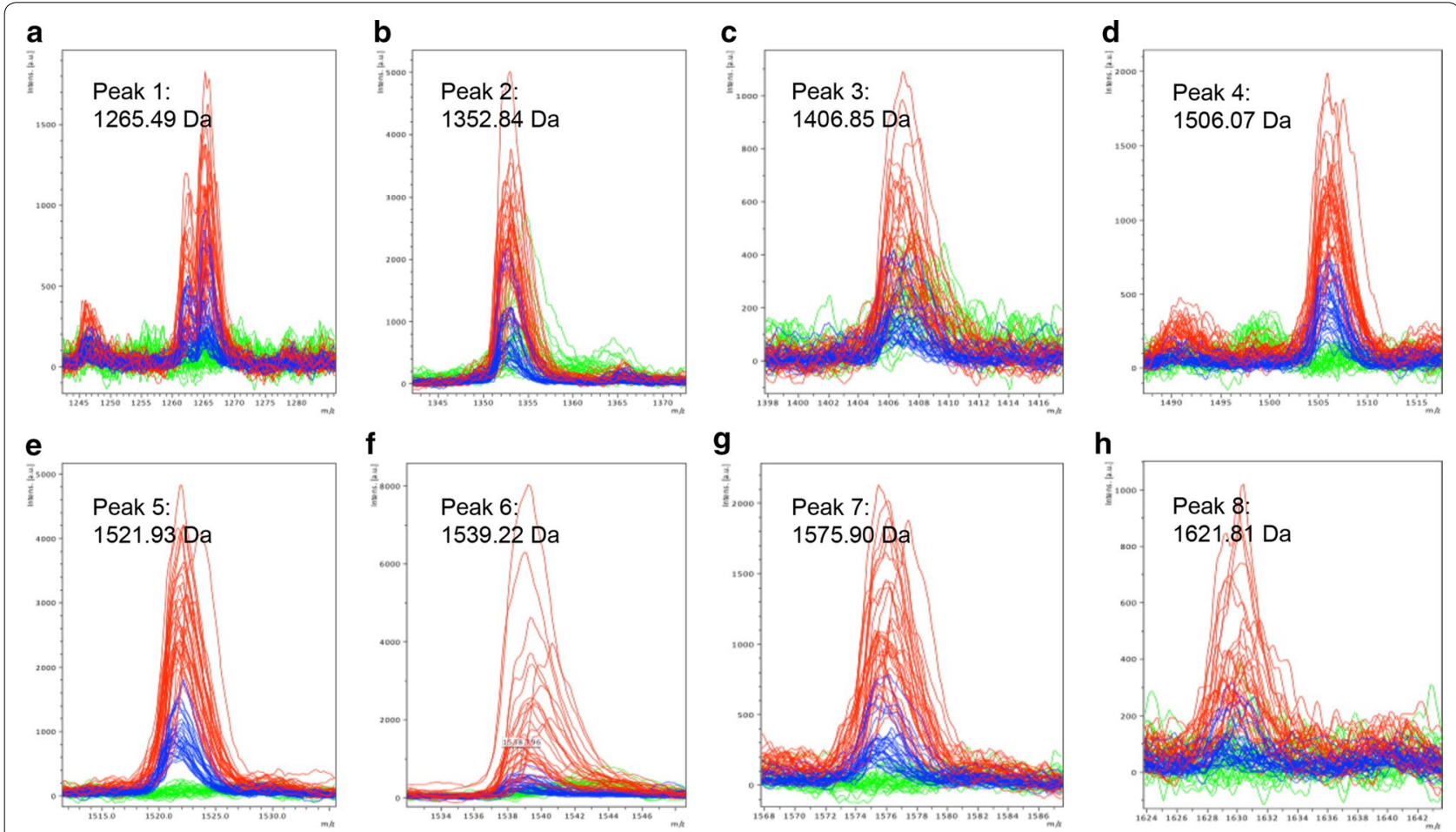

g

$\mathbf{h}$
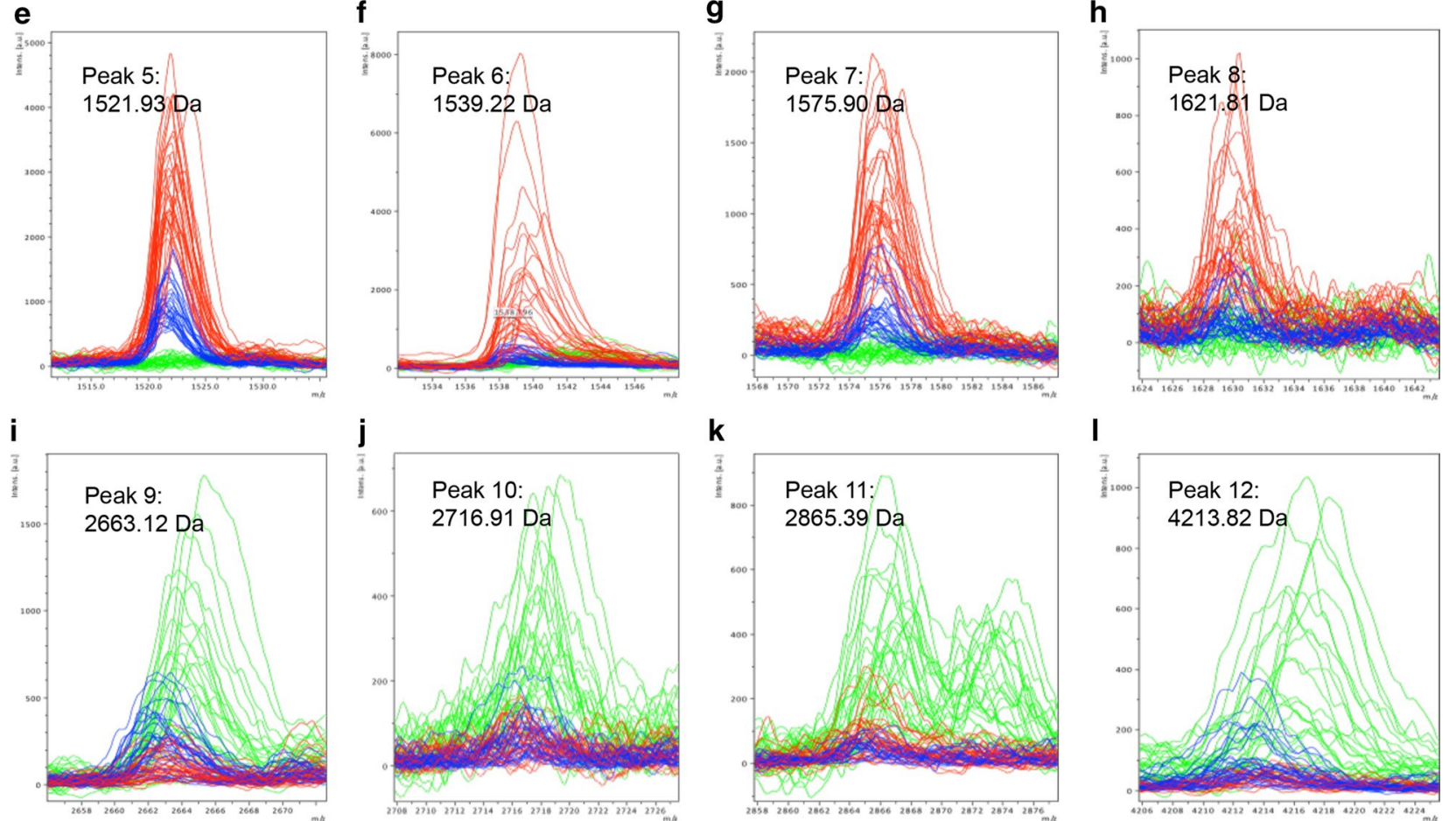

Fig. 2 Comparison of the spectra of the 12 potential peptides in three different groups (red: pre-operative GC patients, blue: post-operative GC patients, green: healthy controls). a Peak 1, m/z: 1265.49 Da; b peak 2, m/z: 1352.84 Da; c peak 3, m/z: 1406.85 Da; d peak 4, m/z: 1506.07 Da; e peak 5, m/z: 1521.93 Da; f peak 6, m/z: 1539.22 Da; g peak 7, m/z: 1575.90 Da; h peak 8, m/z: 1621.81 Da; i peak 9, m/z: 2663.12 Da; j peak 10, m/z: 2716.91 Da; k peak 11, m/z: 2865.39 Da; and I peak 12, m/z: $4213.82 \mathrm{Da}$ 
Table 2 Mean levels of different peptides among healthy controls, pre-operative GC patients and post-operative GC patients

\begin{tabular}{lccccc}
\hline Peaks & Mass $(\mathrm{Da})$ & P value & Control & Pre- & Post- \\
\hline 1 & $1265.49 \uparrow$ & 0.000145 & $2.44 \pm 0.5$ & $12.34 \pm 4.66$ & $9.93 \pm 4.13$ \\
2 & $1352.84 \uparrow$ & 0.000111 & $6.73 \pm 2.91$ & $31.8 \pm 10.48$ & $23.07 \pm 11.08$ \\
3 & $1406.85 \uparrow$ & 0.00222 & $3.98 \pm 1.68$ & $7.2 \pm 2.49$ & $5.57 \pm 1.86$ \\
4 & $1506.07 \uparrow$ & 0.00000893 & $2.09 \pm 0.46$ & $15.42 \pm 4.85$ & $11.60 \pm 3.14$ \\
5 & $1521.93 \uparrow$ & $<0.000001$ & $2.41 \pm 0.43$ & $38.66 \pm 9.47$ & $28.69 \pm 8.36$ \\
6 & $1539.22 \uparrow$ & $<0.000001$ & $3.71 \pm 0.78$ & $24.13 \pm 10.59$ & $11.03 \pm 6.02$ \\
7 & $1575.90 \uparrow$ & 0.000251 & $2.02 \pm 0.44$ & $15.66 \pm 5.49$ & $10.17 \pm 3.96$ \\
8 & $1629.81 \uparrow$ & $<0.000001$ & $2.02 \pm 0.53$ & $6.13 \pm 2.7$ & $4.24 \pm 1.51$ \\
9 & $2663.12 \downarrow$ & 0.0000226 & $6.81 \pm 2.05$ & $2.53 \pm 1.12$ & $6.07 \pm 3.45$ \\
10 & $2716.91 \downarrow$ & 0.0000935 & $3.46 \pm 0.72$ & $1.55 \pm 0.4$ & $2.53 \pm 0.9$ \\
11 & $2865.39 \downarrow$ & $<0.000001$ & $3.3 \pm 1.54$ & $1.71 \pm 0.58$ & $3.42 \pm 2.87$ \\
12 & $4213.82 \downarrow$ & $<0.000001$ & $1.61 \pm 0.98$ & $2.96 \pm 1.36$ \\
\hline
\end{tabular}

suggesting these peptides might be potential biomarkers for GC.

\section{Identification of selected serum peptides in GC patients}

All 12 peptide peaks were further identified using LCESI-MS/MS and human International Protein Index (IPI) database and UniprotKB. The results of peptide fragmentation identification are shown in Table 3. The peaks at m/z 1265.49 Da, 1352.84 Da, 1575.90 Da, 2663.12 Da were identified as Isoform I of Fibrinogen alpha chain precursor (FGA). The peaks at $\mathrm{m} / \mathrm{z} 1506.07 \mathrm{Da}, \mathrm{m} / \mathrm{z}$ $1521.93 \mathrm{Da}, \mathrm{m} / \mathrm{z} 1629.81 \mathrm{Da}, \mathrm{m} / \mathrm{z} 2716.91 \mathrm{Da}, \mathrm{m} / \mathrm{z}$ $2865.39 \mathrm{Da}$ and $\mathrm{m} / \mathrm{z}$ 4213.82 $\mathrm{Da}$ were identified as Alpha-2-HS-glycoprotein precursor (AHSG), Apolipoprotein A-I precursor (APOA-I), Hemoglobin subunit beta (HBB), Isoform 5 of Thioredoxin reductase 1, cytoplasmic (TXNRD1), Cytoskeleton-associated protein 5 (CKAP5) and Eukaryotic peptide chain release factor GTP-binding subunit ERF3B (GSPT2), respectively. The relevant peptide sequences are listed in Table 3. There is no matching information for peptide fragmentation identification of the peak at m/z 1406.85 and m/z 1539.22 in the above databases. The results of identification peptide are shown in Additional file 1.

\section{Validation of expression patterns for three biomarkers in cancers by ELISA}

To validate the selected serum proteins that were identified by proteomics, a validation cohort of $42 \mathrm{GC}$ patients, 30 CRC patients, $30 \mathrm{HCC}$ patients and 28 healthy controls was evaluated in the present study. First, we chose three proteins, FGA, AHSG and APOA-I, according to the relative expression levels of the 12 peptides in three different groups and validated in GC by ELISA (Table 4). Our results revealed that the serum FGA levels were significantly higher in GC patients than in controls, and the ROC analysis showed high diagnostic values of serum FGA in GC with AUCs of 0.98 (Fig. 4a, d). In addition, the serum AHSG and APOA-I levels were noticeably elevated in GC patients compared with controls. Moreover, the ROC analysis also demonstrated high diagnostic values of serum AHSG and APOA-I in GC with AUCs of 0.92 and 0.83 , respectively (Fig. $4 \mathrm{~b}, \mathrm{c}, \mathrm{e}, \mathrm{f}$ ). Finally, to further determine the specificity of FGA, AHSG and APOA-I in GC patients, we examined the serum levels in patients with three common digestive carcinomas (CRC, HCC, and above GC) by ELISA. These three candidates had higher serum levels in GC than in CRC and HCC $(P<0.05$, both) (Fig. $4 \mathrm{~g}, \mathrm{~h}, \mathrm{i})$. All results indicated that FGA, AHSG and APOA-I could be considered valuable diagnostic biomarkers for GC.

\section{Diagnostic values of three biomarkers in GC patients with early or late stage}

We also evaluated the expression patterns of three biomarkers in patients with early- or late-stage GC. A total of 16 patients with early-stage GC (pTNM I+II), 26 patients with late-stage GC (pTNM III + IV), and 28 healthy controls were included. Our results showed that the serum level of FGA was elevated along with GC progression (Fig. 5a). Serum FGA showed favorable diagnostic values for $\mathrm{GC}$ patients both in the early stage (Fig. 5b) and late stage (Fig. 5c). Similarly, the serum level of AHSG was also elevated with an increase in tumor stage (Fig. 5d). The diagnostic value of serum AHSG in GC patients with late-stage GC (Fig. 5f) was significantly higher than in patients with early-stage GC (Fig. 5e). In contrast, the serum level of APOA-I was only elevated in GC patients with early-stage GC (Fig. $5 \mathrm{~g}$ ). The diagnostic value of serum APOA-I was significantly higher 


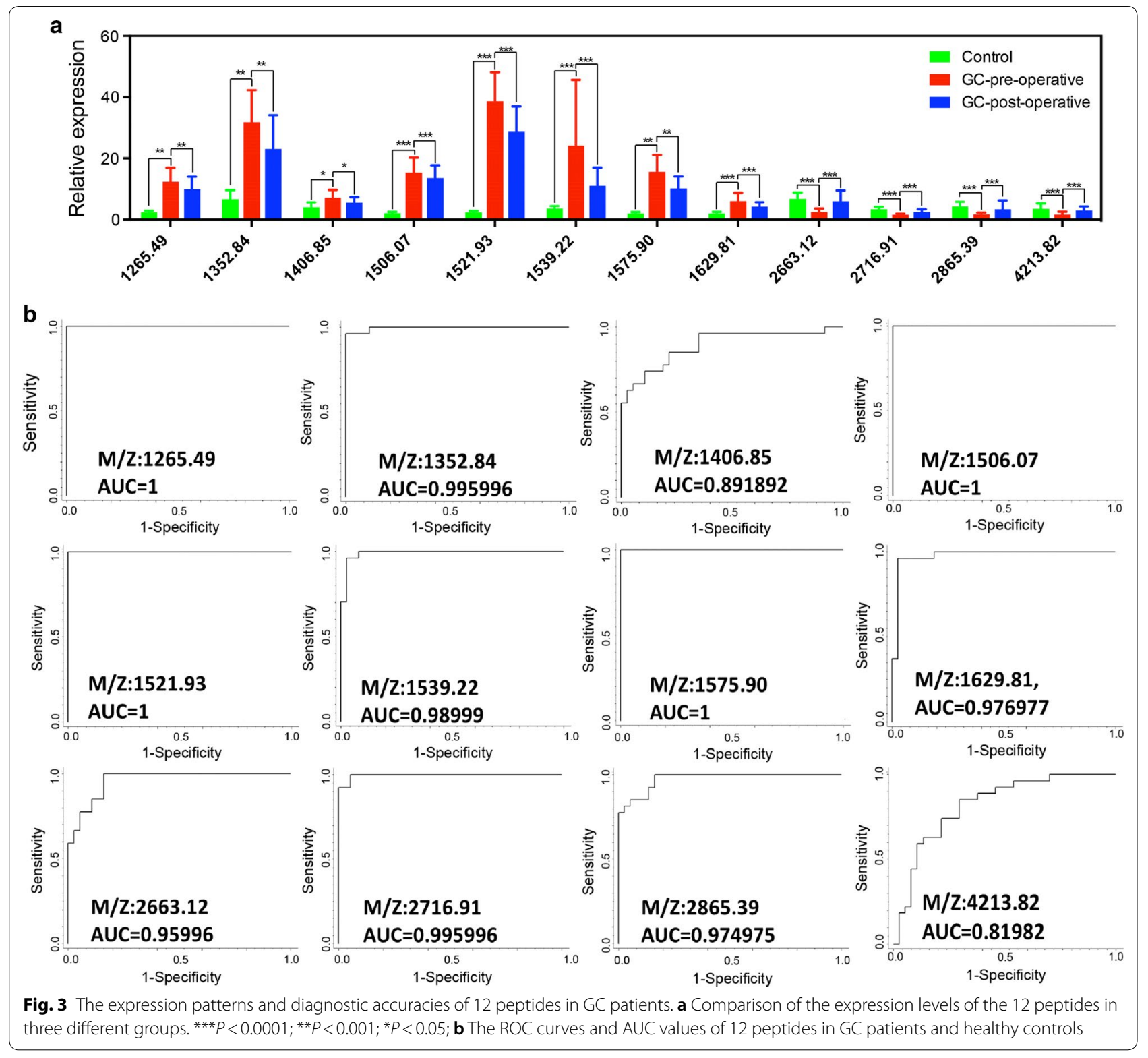

Table 3 Sequence identification of six potential GC biomarkers

\begin{tabular}{llll}
\hline Mass $(\mathbf{m} / \mathbf{z})$ & Peptides sequence & International Protein Index & Identity \\
\hline 1521.93 Da & L.SALEEYTKKLNTQ. & IPI:IPI00021841.1 & Apolipoprotein A-I precursor (APOP-I) \\
1265.49 Da & S.GEGDFLAEGGGVR.G & IPI:IPI00021885.1 & Isoform I of Fibrinogen alpha chain precursor (FGA) \\
1352.84 Da & D.SGEGDFLAEGGGVR.G & & \\
$1575.90 \mathrm{Da}$ & Q.FTSSTSYNRGDSTF.E & & \\
$2663.12 \mathrm{Da}$ & A.DEAGSEADHEGTHSTKRGHAKSRPV.R & & \\
$2716.91 \mathrm{Da}$ & R.WVAQSTNSEEIIEGEYNTVMLAIGR.D & IPI:IPI00554786.5 & Isoform 5 of Thioredoxin reductase 1, cytoplasmic (TXNRD1) \\
4213.82 Da & K.EQSDFCPWYTGLPFIPYLDNL & IPI:IPI00642097.1 & Eukaryotic peptide chain release factor GTP-binding subunit \\
& PNFNRSIDGPIRLPI.V & ERF3B (GSPT2) \\
1506.07 Da & G.WVSLGSPSGEVSHPR.K & IPI:IPI00022431.1 & Alpha-2-HS-glycoprotein precursor (AHSG) \\
1629.81 Da & F.GDLSTPDAVMGNPKVK.A & IPI:IPI00654755.3 & Hemoglobin subunit beta (HBB) \\
2865.39 Da & L.DKIKECSEKVELIHGKKAGLAADKKE.F & IPI:IPI00028275.1 & Cytoskeleton-associated protein 5 (CKAP5) \\
\hline
\end{tabular}


Table 4 The serum expression level of FGA, APOA-1 and AHSG in different groups

\begin{tabular}{llllllll}
\hline & $\begin{array}{l}\text { Control group } \\
(\mathbf{n = 2 8})\end{array}$ & $\begin{array}{l}\text { I/II GC-pre } \\
(\mathbf{n = 1 6 )}\end{array}$ & $\begin{array}{l}\text { III/IV GC-pre } \\
(\mathbf{n = 2 6 )}\end{array}$ & $\begin{array}{l}\text { I/II GC-post } \\
(\mathbf{n}=\mathbf{1 6})\end{array}$ & $\begin{array}{l}\text { III/IV GC-post } \\
(\mathbf{n}=\mathbf{2 6})\end{array}$ & CRC $(\mathbf{n}=\mathbf{3 0})$ & HCC (n=30) \\
\hline FGA $(\mathrm{ng} / \mathrm{ml})$ & $406.80 \pm 42.52$ & $544.05 \pm 53.74$ & $814.19 \pm 85.74$ & $403.54 \pm 46.80$ & $664.13 \pm 63.38$ & $630.94 \pm 96.46$ & $596.70 \pm 67.63$ \\
& $(330.14-490.51)$ & $(447.79-642.26)$ & $(676.96-950.09)$ & $(428.47-598.98)$ & $(556.04-755.03)$ & $(429.35-800.72)$ & $(450.21-779.29)$ \\
AHSG $(\mu \mathrm{g} / \mathrm{ml})$ & $291.83 \pm 47.24$ & $353.74 \pm 49.51$ & $455.79 \pm 59.74$ & $324.74 \pm 41.81$ & $420.17 \pm 53.98$ & $337.34 \pm 49.78$ & $351.26 \pm 41.66$ \\
& $(204.48-375.66)$ & $(244.96-441.11)$ & $(385.38-606.92)$ & $(244.41-401.99)$ & $(354.95-548.11)$ & $(224.17-423.79)$ & $(262.71-441.91)$ \\
AOPA-I $(\mu \mathrm{g} / \mathrm{ml})$ & $3.44 \pm 0.96$ & $5.91 \pm 1.19$ & $3.71 \pm 0.79$ & $4.52 \pm 1.14$ & $3.31 \pm 0.82$ & $3.82 \pm 0.65$ & $2.25 \pm 0.93$ \\
& $(2.03-5.44)$ & $(4.66-8.23)$ & $(2.67-6.19)$ & $(3.21-6.92)$ & $(1.97-5.02)$ & $(2.80-5.67)$ & $(0.84-4.10)$ \\
\hline
\end{tabular}
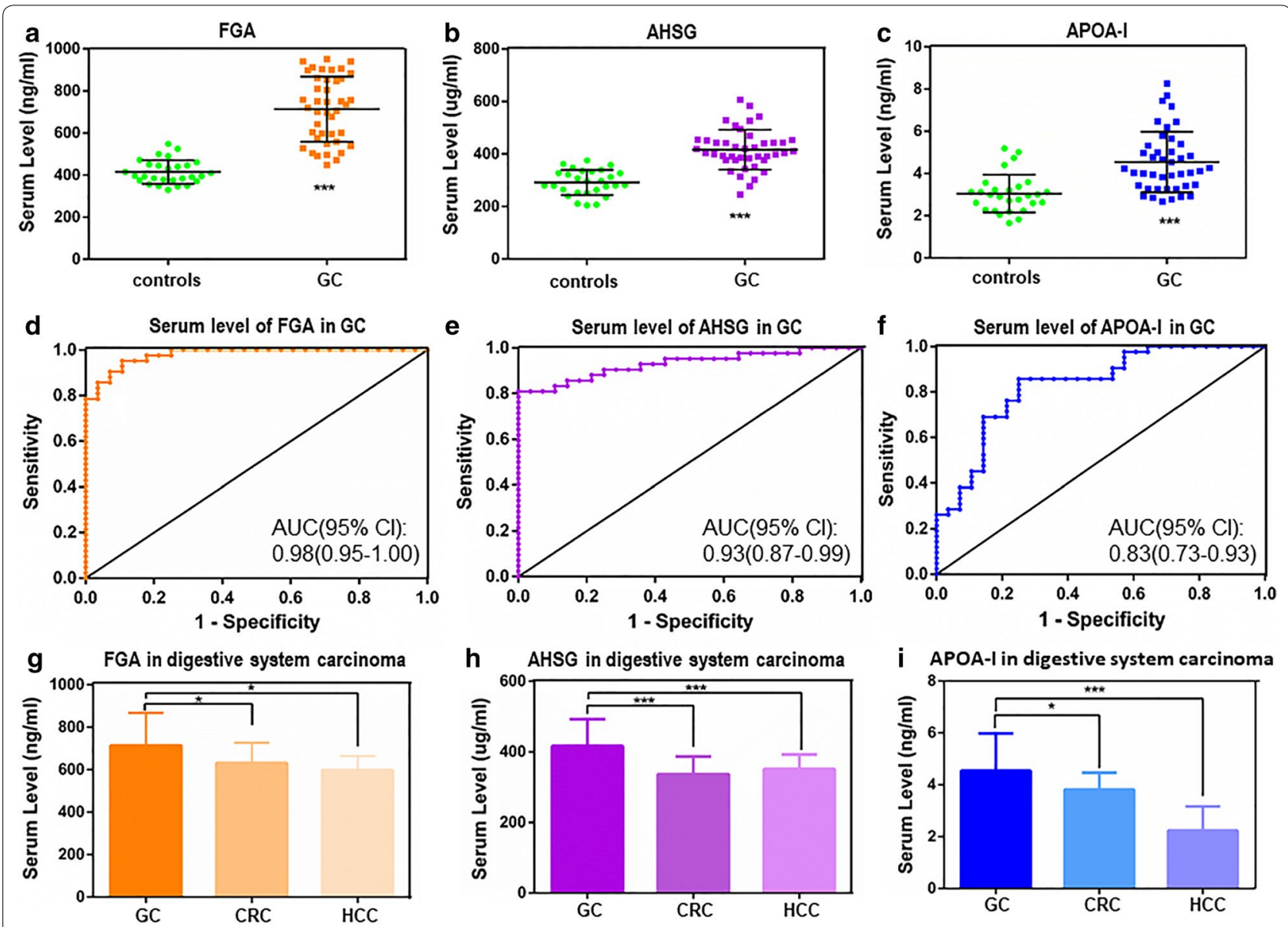

Fig. 4 The expression patterns, diagnostic accuracies and specificity of three proteins. The expression patterns of FGA (a), AHSG (b) and APOA-I (c) in GC patients. ${ }^{* *} P<0.0001$ versus controls; ${ }^{* *} P<0.001$ versus controls; ${ }^{*} P<0.05$ versus controls. The diagnostic accuracies of FGA (d), AHSG (e) and APOA-I ( $\mathbf{f}$ ) in GC patients. The specificity of FGA (g), AHSG (h) and APOA-I (i) in three common digestive system carcinomas, ${ }^{* *} P<0.0001$ versus GC; ${ }^{* *} P<0.001$ versus $G C ; * P<0.05$ versus $G C$

in patients (Fig. 5h) with early-stage GC than those with late-stage GC (Fig. 5i). Furthermore, we also compared the expression levels of three biomarkers between preand post-operation groups. Our results showed that the serum levels of three biomarkers were all decreased after the operation, suggesting that those biomarkers could reflect tumor burden (Fig. 6).

\section{Discussion}

GC is a highly aggressive cancer associated with high mortality in China. Due to the lack of early detection, most GC patients are diagnosed with advanced-stage disease, for which treatment options are limited, resulting in an overall 5-year survival rate of $10-28 \%$ [14]. Serum-based biomarkers are of considerable importance 

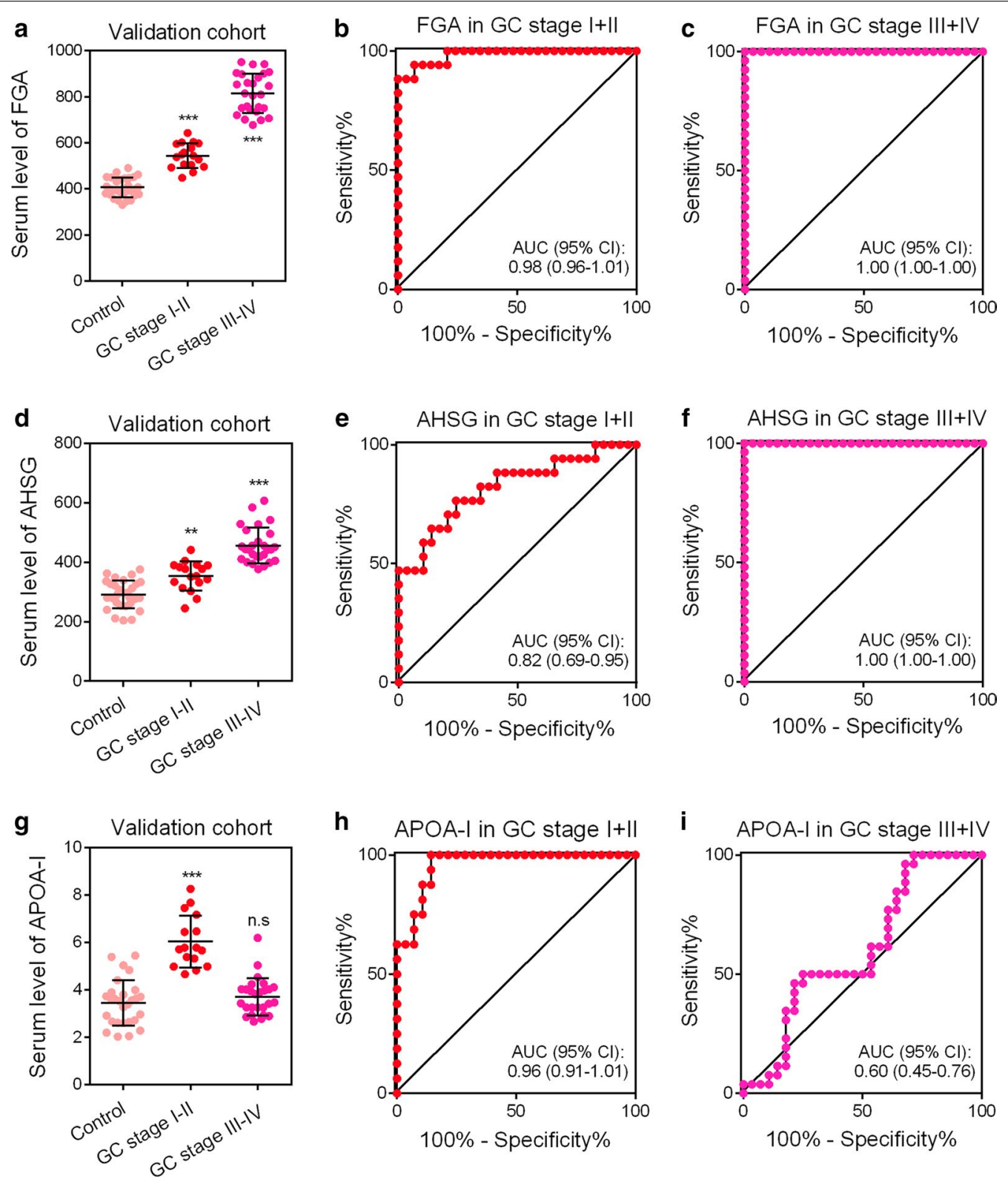

Fig. 5 The diagnostic accuracies of three proteins in patients with different stages of GC. The diagnostic accuracies of FGA (a), AHSG (d) and APOA-I (g) in GC patients. The diagnostic accuracies of FGA (b), AHSG (e) and APOA-I (h) in GC patients with stage I + II GC. The diagnostic accuracies of FGA (c), AHSG (f) and APOA-I (i) in GC patients with stage III + IV GC. ${ }^{* *} P<0.0001$ versus controls; ${ }^{* *} P<0.001$ versus controls; ${ }^{*} P<0.05$ versus controls

in the early diagnosis of various diseases including cancer [10]. Due to the complex mixture in serum samples, the identification of potential tumor biomarkers secreted in very tiny amounts is very difficult $[15,16]$. The development of new proteomics techniques has greatly advanced in this field [17]. The enrichment of protein from serum can be screened with MB-IMAC-Cu, which is designed for extremely sophisticated biomarker profiling studies on a discovery level. Magnetic bead-based fractionation followed by MALDI-TOF-MS combined with advanced bio-informatic tools (ClinProTools software) can identify biomarkers effectively and precisely [18]. In the current study, we employed MALDI-TOF/MS to screen candidate peptides from serum samples. A total of 12 candidate peptides were selected and then identified as the fragment of FGA, AHSG, APOA-I, HBB, CKAP5 and GSPT2 by LC-ESI-MS/MS. In a validation cohort, we confirmed three of them (FGA, AHSG and APOA-I) via ELISA. Our data suggested a relative high diagnostic accuracy of the above three biomarkers in GC patients. 

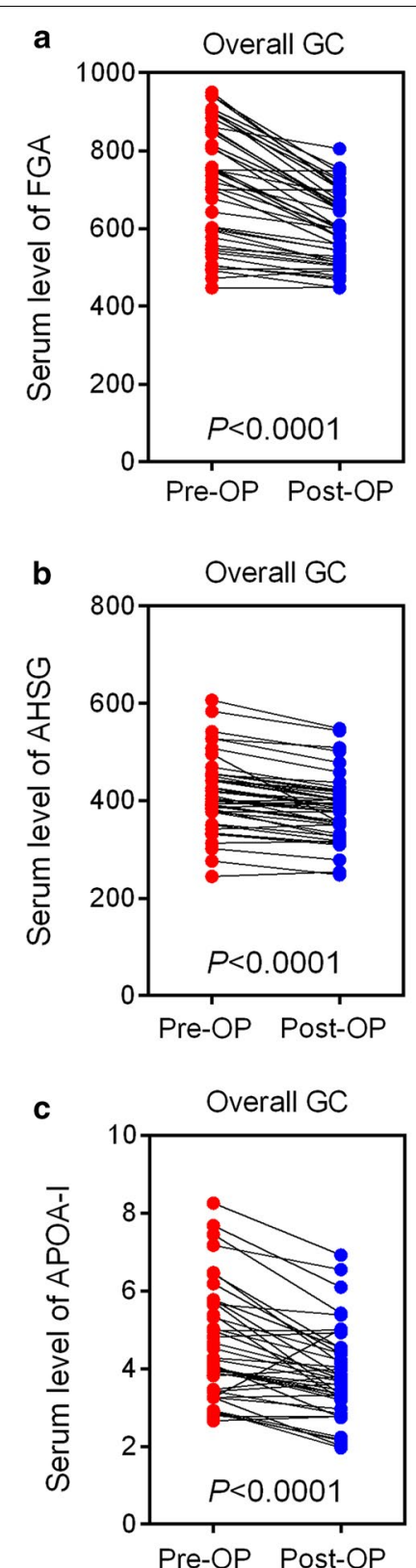
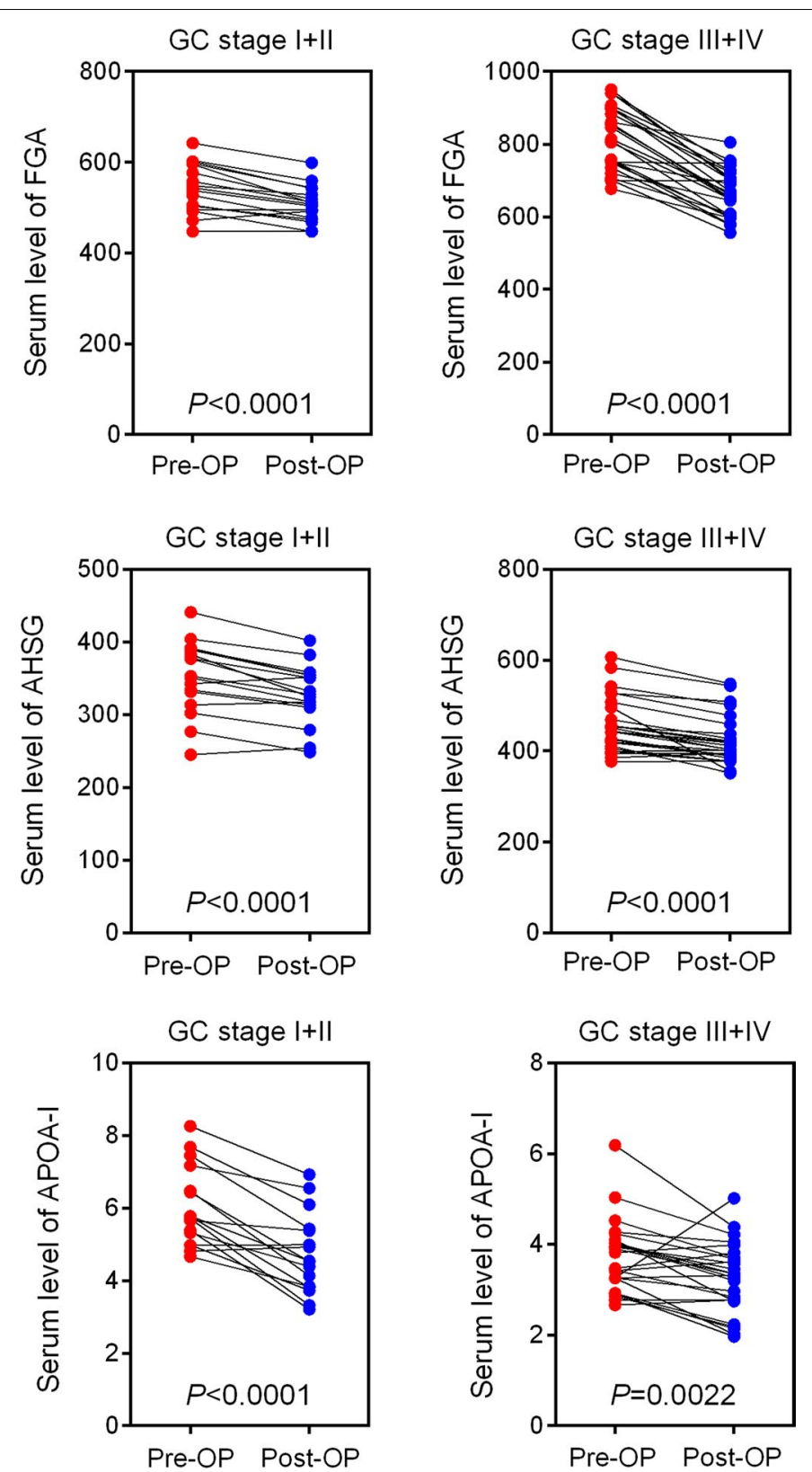

Fig. 6 Comparison of three protein levels between pre- and post-operative groups. a The expression level of FGA in pre- and post-operative groups. $\mathbf{b}$ The expression level of AHSG in pre- and post-operative groups. $\mathbf{c}$ The expression level of APOA-I in pre- and post-operative groups

Alpha 2-HS glycoprotein (AHSG), also known as Fetuin-A, is synthesized by hepatocytes and secreted into the circulatory system [19]. AHSG is a multifunctional glycoprotein involved in numerous normal and pathological processes such as brain development, bone metabolism regulation, insulin resistance, migration and invasion in human colorectal cancer [20]. In addition, AHSG had also been described as a potential diagnostic biomarker for cancer patients. Yi et al. [21] reported that serum AHSG could be used in breast cancer diagnosis. Chen et al. [22] also suggested that the high serum level of AHSG could be a potential biomarker for patients with pancreatic cancer. Moreover, the diagnostic value of AHSG had also been reported in hepatocellular carcinoma [23], glioblastoma [24], esophageal squamous cell carcinoma [25], and prostate cancer [26]. In our study, we reported for the first time that the serum level of AHSG was higher in GC patients than in healthy controls. Our 
data suggested that serum AHSG could be a potential biomarker for GC patients, especially for those patients with late-stage GC.

Fibrinogen alpha chain (FGA) is one of three types of non-identical polypeptide chains consisting of fibrinogen, which is a blood-borne glycoprotein. Comprehensive research indicated that the serum level of FGA was up-regulated in many malignant neoplasms, such as breast cancer, nasopharyngeal carcinoma, acute lymphocytic leukemia, esophageal squamous cell carcinoma and renal cell cancer [27-29]. Our data based on mass spectrometry revealed that 5 out of 12 candidate peptides were identified as FGA. Moreover, in the ELISA-based validation cohort, the serum level of FGA was significantly higher in GC patients than in healthy controls, and serum FGA showed favorable diagnostic accuracy in patients with both early- and late-stage GC. Our finding is consistent with those of previous studies by Liu et al. [30] and Wu et al. [31]. The high serum level of FGA in cancer patients may be due to the release of pro-coagulant factors from endothelial cells and platelets, the latter of which were stimulated by cancer cells [32,33]. In addition, some studies also reported that FGA was involved in tumor progression and metastasis [34], which also suggested that serum FGA could be a potential tumorassociated biomarker to improve the sensitivity of the diagnosis of GC.

Recently, the relationship between apolipoprotein and cancer has been highlighted. Signe Borgquist et al. reported that overall cancer risk is associated with the circulatory content of apolipoproteins in males [35]. Recent studies have also revealed that some apolipoproteins, such as APOC-I [36] and APOC-III [37], were overexpressed in serum samples derived from GC patients. APOA-I, which is produced in the liver and intestine [38], is a primary structural and functional portion of high-density lipoprotein and plays an indispensable role in cholesterol transportation and metabolism homeostasis [39]. Due to its intricate biological functions, APOA-I has been reported to be involved in various pathological processes, such as cardiovascular disease, myeloproliferative disorders and Alzheimer's disease [40]. Moreover, it was observed that APOA-I could be secreted by cancer cells [41, 42], suggesting the tight association between APOA-I and cancer. In the clinic, the diagnostic value of APOA-I as a potential tumor biomarker was also reported in multiple malignancies, such as breast cancer, lung cancer, ovarian cancer, bladder cancer and cholangiocarcinoma [40]. In our study, APOA-I was shown to be up-regulated in GC patients, especially in those with early-stage GC. Moreover, the level of APOA-I was significantly decreased after gastrectomy, suggesting that this biomarker reflects tumor burden. Our findings are consistent with those of a previous study [43] that found an association between the circulating level of APOAI and tumor burden in a mouse model. However, in a previous study by Muntoni et al. [44], the level of serum APOA-I in female GC patients was decreased compared with healthy controls, and there was no significant difference between male GC patients and healthy controls. The inconsistent results in our study and Muntoni's study may be due to the following reasons. First, the apolipoprotein isoforms and the level of lipoprotein were reported to be highly variable and ethnicity-specific [45]. Second, the apolipoproteins were unstable, resulting in the generation of some vulnerable protein fragments during prolonged storage [46]. In Muntoni's study, the collection period of serum samples was more than 10 years (1984-1998). In contrast, our samples were consecutively collected within 10 months, which might reduce the degradation of serum proteins. Finally, the different methods of sample preparation and detection in the two studies could also contribute to the discrepancy, which needs to be validated by a large-sample size and multi-center cohort in the future.

\section{Conclusion}

Twelve peptides were identified as candidate biomarkers for GC patients by high-throughput proteomics. Three of them (FGA, AHSG and APOA-I) were validated in a larger cohort with high diagnostic accuracies, which suggested that FGA, AHSG and APOA-I might be developed as potential diagnostic biomarkers. Meanwhile, all proteins identified are highly abundant serum proteins and the presence of different elevated levels of the proteins in the other cohort, which suggested these candidate biomarkers could probably be secondary biomarkers. Nevertheless, they are still potentially valuable to improve the sensitivity and specificity of the diagnosis of GC. Further reliable validation with bigger sample cohorts is still needed for these three potential GC biomarkers, which might be valuable for the clinical diagnosis of GC in the future. Moreover, further studies will focus on validating the diagnostic accuracies of another four non-validated potential biomarkers (HBB, TXNRD1, CAKP5, GSPT2) and on analyzing the relationships between the expressed levels of those biomarkers and the prognosis of GC patients.

\section{Additional file}

Additional file 1: Supplementary material figures S1-S10. 


\section{Abbreviations}

GC: gastric cancer; CRC: colorectal cancer; HCC: hepatocellular carcinoma; MB-IMAC-Cu: magnetic beads based immobilized metal-ion affinity chromatography; MALDI-TOF/MS: matrix-assisted laser desorption/ionization timeof-flight mass spectrometry; CEA: carcino-embryonic antigen; CA19-9: carbohydrate antigen 19-9; CA72-4: carbohydrate antigen 72-4; AHSG: alpha 2-HS glycoprotein; APOA-l: apolipoprotein A-l; TXNRD1: isoform 5 of thioredoxin reductase 1, cytoplasmic; HBB: hemoglobin subunit beta; GSPT2: eukaryotic peptide chain release factor GTP-binding subunit ERF3B; CAKP5: cytoskeletonassociated protein 5; ELISA: enzyme-linked immunosorbent assay.

\section{Authors' contributions}

JS and YL designed the study. FS, HW, KQ, QS and FL carried out all experiments and data analysis and drafted the manuscript. CS, YL, XX, QQ, TY, XJ and LC collected the samples. QW revised the manuscript. All authors reviewed the final manuscript.

\section{Author details}

${ }^{1}$ Department of General Surgery, The First Affiliated Hospital of Xi'an Jiao Tong University, 277 Yanta West Road, Xi'an 710061, Shaanxi, China. ${ }^{2}$ Department of Hepatobiliary Surgery, The First Affiliated Hospital of Xi'an Jiao Tong University, 277 Yanta West Road, Xi'an 710061, Shaanxi, China. ${ }^{3}$ Department of Talent Highland, The First Affiliated Hospital of Xi'an Jiao Tong University, 277 Yanta West Road, Xi'an 710061, Shaanxi, China. ${ }^{4}$ Department of Cell Biology and Genetics, School of Basic Medical Sciences, Xi'an Jiao Tong University Health Science Center, 76 Yanta West Road, Xi'an 710061, Shaanxi, China. ${ }^{5}$ Department of Developmental and Stem Cell Biology, Hospital for Sick Children, University of Toronto, Toronto, ON M5G0A4, Canada. ${ }^{6}$ Department of Gastroenterology, The First Affiliated Hospital of Xi'an Jiao Tong University, 277 Yanta West Road, Xi'an 710061, Shaanxi, China.

\section{Acknowledgements}

Not applicable.

\section{Competing interests}

The authors declare that they have no competing interests.

\section{Availability of data and materials}

The data and material of this study are available, and requests should be addressed to the corresponding author.

\section{Consent for publication}

All authors consent to the publication of this manuscript.

\section{Ethics approval and consent to participate}

The research protocol was approved by the Ethics and the Human Research Review Committee of Xi'an Jiao Tong University. All subjects signed a consent form before participating in this research study, which was approved by the Institutional Review Board of Xi'an Jiao Tong University. All experiments were carried out in accordance with the approved guidelines.

\section{Funding}

This work was supported by the National Natural Science Foundation of China (No. 81702362), the International Cooperation Program of Shaanxi Province, China (No. 2016KW-004) and the Clinical Research Award of the First Affiliated Hospital of Xi'an Jiaotong University, China (No. XJTU1AF-CRF-2015-029).

\section{Publisher's Note}

Springer Nature remains neutral with regard to jurisdictional claims in published maps and institutional affiliations.

Received: 5 January 2018 Accepted: 18 April 2018 Published online: 30 April 2018

\section{References}

1. Van Cutsem E, Sagaert X, Topal B, Haustermans K, Prenen H. Gastric cancer. Lancet. 2016;388(10060):2654-64.
2. Torre LA, Bray F, Siegel RL, Ferlay J, Lortet-Tieulent J, Jemal A. Global cancer statistics, 2012. CA Cancer J Clin. 2015;65(2):87-108.

3. Zong $\mathrm{L}$, Abe $\mathrm{M}$, Seto $\mathrm{Y}, \mathrm{Ji}$ J. The challenge of screening for early gastric cancer in China. Lancet. 2016;388(10060):2606

4. Roth AD. Curative treatment of gastric cancer: towards a multidisciplinary approach? Crit Rev Oncol Hematol. 2003;46(1):59-100.

5. Krejs GJ. Gastric cancer: epidemiology and risk factors. Dig Dis. 2010;28(4-5):600-3.

6. Coghlin C, Murray Gl. Progress in the development of protein biomarkers of oesophageal and gastric cancers. Proteomics Clin Appl. 2016;10(4):532-45.

7. Leja M, You W, Camargo MC, Saito H. Implementation of gastric cancer screening - the global experience. Best Pract Res Clin Gastroenterol. 2014:28(6):1093-106.

8. Tsai MM, Wang CS, Tsai CY, Chi HC, Tseng YH, Lin KH. Potential prognostic, diagnostic and therapeutic markers for human gastric cancer. World J Gastroenterol. 2014;20(38):13791-803.

9. Ebert MP, Malfertheiner P. Review article: pathogenesis of sporadic and familial gastric cancer-implications for clinical management and cancer prevention. Aliment Pharmacol Ther. 2002;16(6):1059-66.

10. Kulasingam V, Diamandis EP. Strategies for discovering novel cancer biomarkers through utilization of emerging technologies. Nat Clin Pract Oncol. 2008;5(10):588-99.

11. Yang J, Yang J, Gao Y, Zhao L, Liu L, Qin Y, Wang X, Song T, Huang C. Identification of potential serum proteomic biomarkers for clear cell renal cell carcinoma. PLoS ONE. 2014;9(11):e111364

12. Yang J, Xiong X, Wang X, Guo B, He K, Huang C. Identification of peptide regions of SERPINA1 and ENOSF1 and their protein expression as potential serum biomarkers for gastric cancer. Tumour Biol. 2015:36(7):5109-18.

13. Yang J, Zhu J, He K, Zhao LY, Liu LY, Song TS, Huang C. Proteomic profiling of invasive ductal carcinoma (IDC) using magnetic beads-based serum fractionation and MALDI-TOF MS. J Clin Lab Anal. 2015;29(4):321-7.

14. Ferlay J, Steliarova-Foucher E, Lortet-Tieulent J, Rosso S, Coebergh JW, Comber H, Forman D, Bray F. Cancer incidence and mortality patterns in Europe: estimates for 40 countries in 2012. Eur J Cancer. 2013:49(6):1374-403.

15. Anderson NL, Polanski M, Pieper R, Gatlin T, Tirumalai RS, Conrads TP Veenstra TD, Adkins JN, Pounds JG, Fagan R, et al. The human plasma proteome: a nonredundant list developed by combination of four separate sources. Mol Cell Proteomics. 2004;3(4):311-26.

16. Anderson NL, Anderson NG. The human plasma proteome: history, character, and diagnostic prospects. Mol Cell Proteomics. 2002;1(11):845-67.

17. Zolotarjova N, Martosella J, Nicol G, Bailey J, Boyes BE, Barrett WC. Differences among techniques for high-abundant protein depletion. Proteomics. 2005;5(13):3304-13.

18. Palmblad M, Tiss A, Cramer R. Mass spectrometry in clinical proteomicsfrom the present to the future. Proteomics Clin Appl. 2009;3(1):6-17.

19. Stefan N, Hennige AM, Staiger H, Machann J, Schick F, Krober SM, Machicao F, Fritsche A, Haring HU. Alpha2-Heremans-Schmid glycoprotein/ fetuin-A is associated with insulin resistance and fat accumulation in the liver in humans. Diabetes Care. 2006;29(4):853-7.

20. Mori K, Emoto M, Inaba M. Fetuin-A: a multifunctional protein. Recent Pat Endocr Metab Immune Drug Discov. 2011;5(2):124-46.

21. Yi JK, Chang JW, Han W, Lee JW, Ko E, Kim DH, Bae JY, Yu J, Lee C, Yu MH, et al. Autoantibody to tumor antigen, alpha 2-HS glycoprotein: a novel biomarker of breast cancer screening and diagnosis. Cancer Epidemiol Biomarkers Prev. 2009;18(5):1357-64.

22. Chen J, Wu W, Chen L, Zhou H, Yang R, Hu L, Zhao Y. Profiling the potential tumor markers of pancreatic ductal adenocarcinoma using 2D-DIGE and MALDI-TOF-MS: up-regulation of complement C3 and alpha-2-HSglycoprotein. Pancreatology. 2013;13(3):290-7.

23. Wang $K$, Xu X, Nie Y, Dai L, Wang P, Zhang J. Identification of tumor-associated antigens by using SEREX in hepatocellular carcinoma. Cancer Lett. 2009:281(2):144-50.

24. Petrik V, Saadoun S, Loosemore A, Hobbs J, Opstad KS, Sheldon J, Tarelli E, Howe FA, Bell BA, Papadopoulos MC. Serum alpha 2-HS glycoprotein predicts survival in patients with glioblastoma. Clin Chem. 2008;54(4):713-22.

25. Jia K, Li W, Wang F, Qu H, Qiao Y, Zhou L, Sun Y, Ma Q, Zhao X. Novel circulating peptide biomarkers for esophageal squamous cell carcinoma 
revealed by a magnetic bead-based MALDI-TOFMS assay. Oncotarget. 2016;7(17):23569-80.

26. Mintz PJ, Rietz AC, Cardo-Vila M, Ozawa MG, Dondossola E, Do KA, Kim J, Troncoso P, Logothetis CJ, Sidman RL, et al. Discovery and horizontal follow-up of an autoantibody signature in human prostate cancer. Proc Natl Acad Sci USA. 2015;112(8):2515-20.

27. Tao YL, Li Y, Gao J, Liu ZG, Tu ZW, Li G, Xu BQ, Niu DL, Jiang CB, Yi W, et al. Identifying FGA peptides as nasopharyngeal carcinoma-associated biomarkers by magnetic beads. J Cell Biochem. 2012;113(7):2268-78.

28. Yang J, Xiong X, Liu S, Zhu J, Luo M, Liu L, Zhao L, Qin Y, Song T, Huang C. Identification of novel serum peptides biomarkers for female breast cancer patients in Western China. Proteomics. 2016;16(6):925-34.

29. Bai J, He A, Huang C, Yang J, Zhang W, Wang J, Yang Y, Zhang P, Zhang Y, Zhou F. Serum peptidome based biomarkers searching for monitoring minimal residual disease in adult acute lymphocytic leukemia. Proteome Sci. 2014;12(1):49.

30. Liu C, Pan C, Liang Y. Screening and identification of serum proteomic biomarkers for gastric adenocarcinoma. Exp Ther Med. 2012;3(6):1005-9.

31. Wu C, Luo Z, Tang D, Liu L, Yao D, Zhu L, Wang Z. Identification of carboxyl terminal peptide of Fibrinogen as a potential serum biomarker for gastric cancer. Tumour Biol. 2016;37(5):6963-70

32. Seebacher V, Polterauer S, Grimm C, Husslein $\mathrm{H}$, Leipold $\mathrm{H}$, HeflerFrischmuth K, Tempfer C, Reinthaller A, Hefler L. The prognostic value of plasma fibrinogen levels in patients with endometrial cancer: a multicentre trial. Br J Cancer. 2010;102(6):952-6.

33. Gouin-Thibault I, Achkar A, Samama MM. The thrombophilic state in cancer patients. Acta Haematol. 2001;106(1-2):33-42

34. Palumbo JS, Kombrinck KW, Drew AF, Grimes TS, Kiser JH, Degen JL, Bugge TH. Fibrinogen is an important determinant of the metastatic potential of circulating tumor cells. Blood. 2000;96(10):3302-9.

35. Borgquist S, Butt T, Almgren P, Shiffman D, Stocks T, Orho-Melander M, Manjer J, Melander O. Apolipoproteins, lipids and risk of cancer. Int J Cancer. 2016;138(11):2648-56

36. Yamamoto-Ishikawa K, Suzuki H, Nezu M, Kamiya N, Imamoto T, Komiya A, Sogawa K, Tomonaga T, Nomura F, Ichikawa T. The isolation and identification of apolipoprotein $\mathrm{C}-\mathrm{I}$ in hormone-refractory prostate cancer using surface-enhanced laser desorption/ionization time-of-flight mass spectrometry. Asian J Androl. 2009;11 (3):299-307.

37. Song D, Yue L, Li H, Zhang J, Yan Z, Fan Y, Yang H, Liu Q, Zhang D, Xia Z, et al. Diagnostic and prognostic role of serum protein peak at $6449 \mathrm{~m} / \mathrm{Z}$ in gastric adenocarcinoma based on mass spectrometry. Br J Cancer. 2016;114(8):929-38.

38. Wang X, Dai S, Zhang Z, Liu L, Wang J, Xiao X, He D, Liu B. Characterization of apolipoprotein A-I as a potential biomarker for cholangiocarcinoma. Eur J Cancer Care (Engl). 2009:18(6):625-35.

39. Wasan KM, Brocks DR, Lee SD, Sachs-Barrable K, Thornton SJ. Impact of lipoproteins on the biological activity and disposition of hydrophobic drugs: implications for drug discovery. Nat Rev Drug Discov. 2008;7(1):84-99.

40. Mangaraj M, Nanda R, Panda S. Apolipoprotein A-I: a molecule of diverse function. Indian J Clin Biochem. 2016;31(3):253-9.

41. Yamamoto T, Suda M, Moriwaki Y, Takahashi S, Higashino K. Novel apoprotein A-I-containing lipoprotein produced by a human hepatoma-derived cell line HuH-7. Biochim Biophys Acta. 1990;1047(1):49-56.

42. Chisholm JW, Burleson ER, Shelness GS, Parks JS. ApoA-I secretion from HepG2 cells: evidence for the secretion of both lipid-poor apoA-I and intracellularly assembled nascent HDL. J Lipid Res. 2002;43(1):36-44.

43. Chong PK, Lee H, Zhou J, Liu SC, Loh MC, So JB, Lim KH, Yeoh KG, Lim Y. Reduced plasma APOA1 level is associated with gastric tumor growth in MKN45 mouse xenograft model. J Proteomics. 2010;73(8):1632-40.

44. Muntoni S, Atzori L, Mereu R, Satta G, Macis MD, Congia M, Tedde A, Desogus A, Muntoni S. Serum lipoproteins and cancer. Nutr Metab Cardiovasc Dis. 2009:19(3):218-25.

45. Lee SR, Prasad A, Choi YS, Xing C, Clopton P, Witztum JL, Tsimikas S. LPA gene, ethnicity, and cardiovascular events. Circulation. 2017;135(3):251-63

46. Gast MC, van Gils CH, Wessels LF, Harris N, Bonfrer JM, Rutgers EJ, Schellens JH, Beijnen JH. Influence of sample storage duration on serum protein profiles assessed by surface-enhanced laser desorption/ionisation time-of-flight mass spectrometry (SELDI-TOF MS). Clin Chem Lab Med. 2009;47(6):694-705
Ready to submit your research? Choose BMC and benefit from:

- fast, convenient online submission

- thorough peer review by experienced researchers in your field

- rapid publication on acceptance

- support for research data, including large and complex data types

- gold Open Access which fosters wider collaboration and increased citations

- maximum visibility for your research: over $100 \mathrm{M}$ website views per year

At $\mathrm{BMC}$, research is always in progress.

Learn more biomedcentral.com/submissions 